\title{
Conteúdo web acessível às pessoas com deficiência visual: pesquisa e criação de e-book informativo aos desenvolvedores
}

\author{
Raissa Sabino Cunha \\ Instituto Federal de Educação, Ciência \\ e Tecnologia de São Paulo, Campus \\ Votuporanga \\ Votuporanga - SP \\ ra6sabino@gmail.com
}

\author{
Prof. Dra.Luciene Cavalcanti Rodrigues \\ Instituto Federal de Educação, Ciência \\ e Tecnologia de São Paulo, Campus \\ Votuporanga \\ Votuporanga - SP \\ prof.luciene@ifsp.edu.br
}

\begin{abstract}
The project aims to raise the awareness of current and future generations about the importance of accessibility in digital media through instructive methods, in order to collaborate with Brazilian digital inclusion laws. The proposal is to present the difficulties that visually impaired people have in digital media, developing an educational e-book for web developers in order to guide the necessary care during the elaboration of their projects so that they implement the accessibility recommendations and allow interaction of people with some limitation, thus promoting greater reach and inclusion of these individuals. The e-book was built taking into account a survey conducted with web developers, after the ebook was made available the link sent to respondents in order to verify the quality of the final result of the project.

Keywords: Web accessibility; Visually impaired; Digital inclusion.

Resumo: O projeto visa despertar a conscientização das gerações atuais e futuras sobre a importância da acessibilidade nos meios digitais através de métodos instrutivos, no sentido de colaborar com as leis brasileiras de inclusão digital. A proposta é apresentar as dificuldades que os deficientes visuais possuem no meio digital, elaborando um e-book educativo para desenvolvedores Web de forma a orientar os cuidados necessários durante a elaboração de seus projetos para que esses implementem as recomendações de acessibilidade e permitam interação de pessoas com alguma limitação, assim, promovendo maior alcance e inclusão destes indivíduos. O e-book foi construído levando-se em conta uma pesquisa realizada com desenvolvedores Web, após disponibilizado o e-book o link foi enviado aos respondentes de forma a verificar a qualidade do resultado final do projeto.
\end{abstract}

Palavras-chaves: Acessibilidade web; Deficiente visual; Inclusão digital.

\section{INTRODUÇÃO}

No Brasil, um exemplo de ascensão de acessibilidade é a construção obrigatória de rampas em espaços físicos para facilitar a locomoção, tanto de pessoas que usam cadeiras de rodas, como para qualquer indivíduo que encontre dificuldades de subir escadas. No meio digital, a criação de websites sem obedecer aos padrões acessíveis de desenvolvimento, por exemplo, pode custar caro para uma instituição ou empresa, com a ausência de potenciais consumidores, por conseguinte, perda de receita. De acordo com Freitas (2019), as dificuldades de acessibilidade mais graves se relacionam aos usuários cegos e com baixa visão, vez que a maioria das páginas web são visuais.
Acessibilidade significa facilidade de aproximação. A acessibilidade e a inclusão estão intimamente ligadas. (PETERSEN; KALEMPA; PYKOSZ, 2013). A consciência das limitações existentes e viabilidade de pessoas com deficiências visuais está crescendo, como também a luta por inclusão social se amplia constantemente. Os desenvolvedores de páginas e conteúdo para internet têm um papel importante nessa integração, visto que, ao tornar um site acessível, podem ser capazes de garantir uma boa experiência durante a navegação, cooperando com a inclusão de públicos historicamente excluídos, como os deficientes visuais, ao acesso à informação. Ocorre, entretanto, que grande parte ainda possui desinformação a respeito das normas de acessibilidade e principalmente há a necessidade de as aplicar.

A visão se apresenta como um canal muito importante no relacionamento dos indivíduos com o mundo atual, no entanto, ao mesmo tempo, em que é tratada como o principal meio de exercer interações, notamos que existe um grande número de pessoas com visão parcial ou totalmente reduzidas. Segundo dados do IBGE (2010), no Brasil, das mais de 6,5 milhões de pessoas com alguma deficiência visual: 528624 indivíduos são incapazes de enxergar (cegos) e 6.056.654 possuem visão baixa ou subnormal. Ademais, com o aumento da expectativa de vida, algumas doenças que antes eram atípicas se tornam frequentes pois, à medida que se envelhece, alguns órgãos podem ficar mais suscetíveis ao surgimento de debilidades, seja auditiva, motora ou visual, como a presbiopia, também conhecida como vista cansada, uma condição que ocorre em maior parte das pessoas após os 40 anos.

Outrossim, a ascensão de novas tecnologias trouxe uma série de facilidades em vários aspectos do cotidiano humano. A Internet constitui, sem dúvida, o maior instrumento de informação da atualidade (BAPTISTA, 2017). Uma vez que trouxe a possibilidade de ter acesso imediato a uma gama de informações de todos os assuntos e de qualquer parte do mundo, transformou a forma de comunicação, de entretenimento ou de trabalho, acessá-la se tornou algo indispensável. No entanto, permanece restrita aos que conseguem acessá-la. Indivíduos com alguma deficiência ou limitação enfrentam problemas com a ausência de acessibilidade ao tentar navegar por essa grande rede, ficando assim, limitados de exercer seus papéis sociais, sua cidadania, autonomia e participação ativa no mundo que o cerca, que hoje é basicamente digital. 
A Constituição Brasileira (1988) e a Lei n. ${ }^{\circ} 10.098 / 2000$ regulamentada pelo Decreto n. ${ }^{\text {o }} 5296 / 2004$ garantem aos deficientes e portadores de necessidades especiais, todos os direitos de cidadão comum, visando eliminar as formas de exclusão a esses indivíduos. Ademais, a Lei Brasileira de Inclusão da Pessoa com Deficiência n. ${ }^{\circ} 13.146 / 2015$, torna obrigatória a acessibilidade nos sítios da internet mantidos por empresas com sede ou representação comercial no País. Contudo, ainda é possível observar que mesmo com a legislação em prol, muitas vezes, não se percebe esse processo na prática.

O presente projeto tem por principal objetivo levantar, analisar e documentar a importância de atender aos requisitos de acessibilidade para pessoas com deficiência visual ao desenvolver conteúdo ou páginas web e assim elaborar um ebook de forma a auxiliar os desenvolvedores a trabalhar com acessibilidade em seus projetos.

\section{MATERIAIS E MÉTODOS}

A primeira fase tratou de pesquisa fundamentalmente baseada em levantamento bibliográfico. Este levantamento foi realizado por meio de entrevistas e de revisão bibliográfica de livros, periódicos e artigos sobre os temas para tanto os materiais utilizados foram computador com acesso à internet, livros e periódicos, impressora para impressão de relatórios e artigos finais.

A pesquisa teve início com o levantamento e revisão bibliográfica sobre os elementos de estudo: a percepção do mundo através dos sentidos, em especial, do sentido da visão, bem como sua redução durante o processo de envelhecimento; a inclusão de pessoas com deficiência no Brasil, as legislações pertinentes e a conceituação atual de deficiência; as dificuldades que deficientes visuais enfrentam no meio digital e o uso das tecnologias assistivas para a eliminação dessas barreiras; a introdução da temática de acessibilidade web, normas e diretrizes existentes que agem em relação ao público deficiente visual; e uma análise do cenário atual, trazida para este resumo, com a colaboração de deficientes visuais e desenvolvedores web.

A segunda fase tratou-se da produção do e-book educativo utilizando editor de texto e de imagens.

\section{RESULTADOS E DISCUSSÃO}

Dentre as formas de compreender o mundo externo, a visão é o sentido dominante nos seres humanos, esta proporcionaria muito mais informação que os demais sentidos, através do ambiente visual, são construídas as relações de espaço, distância, textura, luz, cor, forma, contraste e todas as demais formas de apreensão do espaço arquitetônico (RAPOPORT, 1978; TUAN, 1983; KOHLSDORF, 1996, apud KANASHIRO, 2003). Tal como a audição, a visão capta registros próximos ou distantes e permite organizar, no nível cerebral, as informações trazidas pelos outros órgãos dos sentidos (MEC). No entanto, independente de desses aspectos, não há comprovação de que a visão é o sentido mais importante entre os demais, mas sim o mais utilizado e estimulado, se por algum motivo os outros estímulos fossem mais frequentes, como acontece com pessoas com algum tipo de deficiência visual, essa situação poderia ser diferente (GAZZANIGA, IVRY E MAGUN, 2006, apud NAVARRO, 2012).
Outra questão a ser analisada é a redução da visão conforme o envelhecimento do ser humano. Seguindo a estimativa da Agência Internacional para a Prevenção da Cegueira (AIPC), apresentados por Ottaiano, Ávila, Umbelino e Taleb (2019) no Conselho Brasileiro de Oftalmologia, a maior porcentagem de prevalência de indivíduos com ausência de visão são os idosos. Haja vista que, na medida que se envelhece, os olhos podem ficar mais suscetível ao surgimento de debilidades. $\mathrm{Na}$ visão, várias alterações orgânicas comumente manifestadas durante o envelhecer levam à diminuição da acuidade visual, a qual pode ser ou não restabelecida (GASPARET-TO, 2020). Constata-se que o Brasil apresenta uma das maiores taxas de crescimento da população idosa entre os países mais populosos do mundo. De acordo com o IBGE (2010), o índice de envelhecimento aponta para mudanças na estrutura etária da população brasileira, em 2050, a população idosa ultrapassará os 22,71\% da população total. Dentre os desafios que esse veloz crescimento da população idosa traz, está o crescimento da prevalência de problemas visuais, como a Degeneração Macular Relacionada à Idade (DMRI) (OTTAIANO; ÁVILA; UMBELINO; TALEB, 2019).

No Brasil, o IBGE (2010) evidenciou que quase 46 milhões de brasileiros, cerca de $24 \%$ da população, declarou ter algum grau de dificuldade em pelo menos uma das habilidades investigadas (enxergar, ouvir, caminhar ou subir degraus), ou possuir deficiência mental/intelectual. Como pode ser visto no gráfico do Censo 2010 na Fig. 1, em 2010 $18,8 \%$ da população apresentou ter dificuldade para enxergar; $7,0 \%$ tinha dificuldade em se movimentar; e $5,1 \%$ possuía dificuldade para ouvir. E, mesmo que haja escassez de dados populacionais em várias regiões como mostra um levantamento de dados realizado pelo Instituto Brasileiro de Geografia e Estatística (IBGE) em parceria com o Ministério da Saúde, apresentados na Pesquisa nacional de saúde (2013), ainda apontam que pelo menos $6,2 \%$ da população brasileira possui pelo menos uma deficiência.

\section{Porcentagem da população, por tipo e grau} de dificuldade e deficiência (Brasil - 2010)

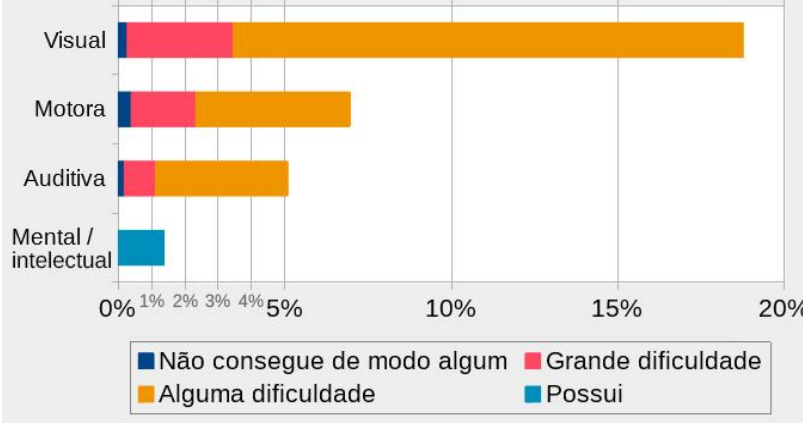

Observação: mesma pessoa pode ter mais de uma deficiência.

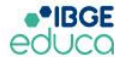

Fonte: IBGE, Censo Demográfico 2010

Fig. 1. Porcentagem da população, por tipo e grau de dificuldade e deficiência- Fonte: IBGE, 2018

Por um longo período a melhor palavra para caracterizar a relação da sociedade com a pessoa com necessidades especiais seria exclusão (SONZA, 2013). A postura do corpo social com relação a estes indivíduos foram se modificando de acordo com a cultura, as crenças, fatores sociais e econômicos. Com o passar do tempo surgiu a preocupação em incluir os seres 
humanos com limitações para que pudessem levar uma vida digna, afinal, as pessoas portadoras de deficiências não são incapazes. Conforme Gil (2000) apresenta, elas podem ter dificuldades para realizar algumas atividades, mas possuírem extrema habilidade em outras como todos os seres humanos que possuem habilidades e talentos característicos, nas pessoas com deficiência, essas manifestações são apenas mais visíveis e mais acentuadas. Sendo assim, em conformidade com a Constituição de 1988, que prevê o pleno desenvolvimento dos cidadãos, sem preconceito de origem, raça, sexo, cor, idade e quaisquer outras formas de discriminação.

Destarte, legislações foram criadas a fim de possibilitar independência às pessoas com deficiência. Como, por exemplo a Lei n. ${ }^{\circ}$ 10.098/2000, regulamentada pelo Decreto n. ${ }^{\circ} 5296 / 2004$, que estabelece normas gerais e critérios básicos para a promoção da acessibilidade das pessoas portadoras de deficiência ou com mobilidade reduzida. Recentemente a Lei n. ${ }^{\circ} 13.146$ de 2015 que se Institui a Lei Brasileira de Inclusão da Pessoa com Deficiência (Estatuto da Pes-soa com Deficiência) veio consolidar os direitos conquistados por essas pessoas, bem como trazer novos direitos e diretrizes. E, o Decreto n. ${ }^{\circ}$ 9.522, de 2018 onde a República Federativa do Brasil firmou o Tratado de Marraqueche para facilitar às pessoas com deficiência visual ou com outras dificuldades para ter acesso ao texto impresso de obras publicadas.

A Lei Brasileira de Inclusão da Pessoa com Deficiência 13.146 (Brasil, 2015), em seu artigo 63, torna obrigatória a acessibilidade nos sítios da internet mantidos por empresas com sede ou representação comercial no País ou por órgãos de governo. Para uso da pessoa com deficiência, garantindo-lhe acesso às informações disponíveis, conforme as melhores práticas e diretrizes de acessibilidade adotadas internacionalmente. Desta forma, qualquer distinção, restrição ou exclusão, por ação ou omissão, incluindo a recusa de adaptações razoáveis e de fornecimento de tecnologias assistivas é considerada uma espécie de discriminação em razão da deficiência, capaz de pena de reclusão, de um a três anos, e multa.

A maioria da população ainda não sabe o que é, nem que importância tem, a acessibilidade associada aos meios de informação, incluindo as pessoas com deficiência que não se utilizam de tecnologias específicas para tornar o acesso a elas pleno e possível (FREITAS,2019). Entretanto, seu avanço traz benefícios para todos, como, por exemplo, tornar possível a comunicação por telefone com uma pessoa surda, apesar desse meio de comunicação ser predominantemente auditivo; ou até mesmo permitir que cegos escrevam, leiam e naveguem de maneira autônoma por um meio sobretudo visível como a internet. É de suma importância ações para pessoas com deficiência ou algum tipo de debilidade, em todos os lugares, concedendo as mesmas oportunidades de participação social, direito à educação, à informação, ao emprego, à saúde e bemestar, sem discriminações, incluindo no meio digital.

As tecnologias de informações e a digitalização da informação são as maiores conquistas dos deficientes visuais, pois permitem o acesso à gama cada vez maior de informação (PASSOS; VIEIRA, 2008). Entre as prin-cipais ferramentas que permitem a criação de condições para a plena inclusão do deficiente visual na sociedade estão também as tecnologias digitais e o advento da Internet (NAVARRO, 2012). De acordo com Schweitzer (2007 apud BORGES, 1996) além de se informar sobre produtos e serviços, a internet permite uma gama de possibilidades, como a comunicação sem a necessidade de locomoção, e o fato de que numa comunicação inicial, a pessoa cega é vista como uma pessoa não deficiente, ficando assim, livre de possíveis preconceitos e, assim disso, há possibilidade de trocar de experiências com outros usuários com condições semelhantes de qualquer lugar do mundo. Schweitzer (2007 apud BORGES, 1996) defende que a inclusão da pessoa cega na sociedade pode ser feita por meio de uma educação adaptada às suas limitações e de tecnologias que visam eliminar essas barreiras, conhecidas como tecnologias assistivas.

Existem atualmente diversas tecnologias assistivas, desde artefatos simples até mais específicos, que possibilitam o acesso de pessoas com deficiência ao uso do computador de acordo com a necessidade de cada pessoa. Algum desses são equipamentos que permitem ao usuário controlar o computador apenas com os movimentos da cabeça, impressoras Braille, teclados com teclas maiores, teclados para escrita de libras, ampliadores, navegador por voz ou leitores de telas, como por exemplo o JAWS e NVDA que contemplam alguns atalhos de acessibilidade para facilitar a navegação, mas dependem que o site siga as normas de desenvolvimento para todos os atalhos funcionem normalmente.

A WebAIM (2017) realizou uma pesquisa questionando usuários com cegueira, baixa visão, deficiência motora, auditiva, cognitiva e normais que fazem o uso de software do tipo Leitor de tela. Com relação à experiência no uso desse software foi perguntado o que teria maior impacto na acessibilidade (Fig. 2) é notável que a maioria dos usuários esperam por sites mais acessíveis do que tecnologias assistivas.

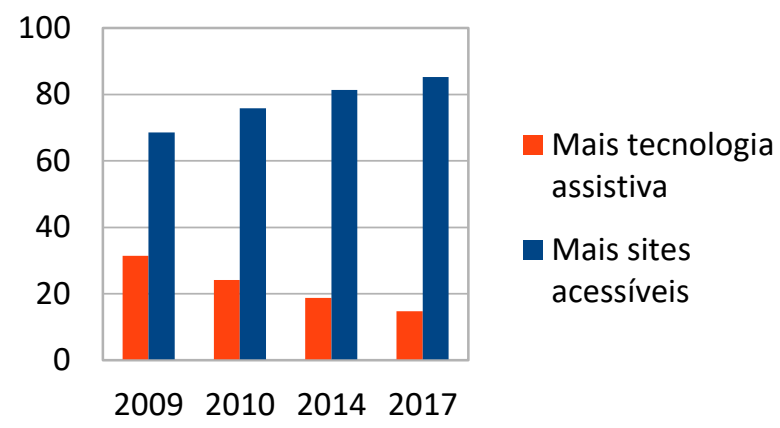

Fig. 2. Qual dos seguintes vocês acha que teriam um impacto maior nas melhorias na acessibilidade da web?. Fonte: WebAIM (2017).

Portanto, apesar do avanço das tecnologias, ainda existem barreiras. Somente os recursos da tecnologia assistiva não são capazes de garantir o acesso ao conteúdo de uma página web. Existem um grande número de deficientes que enfrentam dificuldades no meio digital devido à falta de acessibilidade de sites e softwares, pessoas que podem simplesmente deixar de acessar um site ou aplicação inacessível, que caso fossem projetados com acessibilidade, poderiam usa-los de maneira plena e efetiva e se tornar potenciais compradores, consumidores de serviços e produtos digitais. Para tal, é necessário que os desenvolvedores tenham consciência de que existem usuários que não podem utilizar teclado ou mouse e/ou que necessitam de tecnologias assistivas específicas associadas e necessárias à navegação, sendo fundamental que 
o desenvolvimento esteja de acordo com recomendações de acessibilidade.

A acessibilidade é o termo usado para descrever problemas de usabilidade encontrados por usuários com necessidades especiais (Sonza, 2013). Acessibilidade Web, por sua vez, consiste em tornar um site utilizável por qualquer pessoa, independente de alguma deficiência ou mobilidade reduzida, promovendo condições suficientes para utilização dos meios de informação.

Os principais problemas encontrados por usuários portadores de deficiência visual, de acordo com Nascimento (2015), estão em obter informações apresentadas visualmente, tais como interagir usando um equipamento diferente do teclado, reconhecer cores em destaque facilitando a navegabilidade e diferenciar rapidamente links em documentos.

Existem algumas diretrizes que tratam da eliminação de barreiras para pessoas incapacitadas e devem ser seguidas durante a programação de um site de forma que facilitem a navegação de todos os usuários como, por exemplo, o WCAG (Web Content Accessibility Guidelines), um guia de diretrizes para acessibilidade do conteú-do web de referência mundial que apresenta diversas recomendações publicado pela W3C Web Accessibility Initiative (WAI), resolução da World Wide Web Consortium (W3C), uma das principais organizações de padronização da Web, que tem por finalidade estabelecer padrões para a criação e a interpretação de conteúdos para a Web que quando seguidos possibilitam o acesso a página por qualquer usuário. No Brasil, o Governo Federal criou o e-MAG (Modelo de Acessibilidade do Governo Eletrônico), uma cartilha para auxiliar os desenvolvedores web a tornar o conteúdo dos sites governamentais acessível.

Por fim, é possível notar a aderência de acessibilidade em alguns sites. Como exemplo a página da rede social Facebook que, após reclamações de usuários, passou a integrar recursos que ajudam as pessoas com deficiência a tirar o máximo proveito de sua página. Contudo, alguns sites como o próprio sistema SUAP: Sistema Unificado de Administração Pública, o sistema oficial que os estudantes dos cursos Técnicos, Integrados e Superiores utilizam para realizar vários recursos, não permite uma navegação clara pelo teclado, de forma que o usuário não sabe o que está selecionando ao tentar percorrer a página.

O Movimento Web para Todos (MWPT) em parceria com a BigData Corp, analisou e realizou testes em cerca de 14 milhões de sites ativos do Brasil para verificar a existência de elementos com barreiras às pessoas com deficiência. Segundo a pesquisa do MWPT (2019), 52,38\% dos sites avaliados não atendem aos critérios para acessibilidade de formulários, $83,25 \%$ não atendem aos critérios para acessibilidade em imagens, 83,56\% não atendem aos critérios para acessibilidade em links, $95 \%$ não estão em conformidade com o padrão HTML do W3C e $99,66 \%$ dos sites governamentais (os que estão sob o ccTLD “. gov.br”) não atendem os critérios verificados. Em conclusão, obtiveram que menos de 1\% dos sites analisados passaram nos testes de acessibilidade e a maioria dos endereços on-line do País apresentaram falhas em algum dos testes realizados, mas pontuaram positivamente em outros.

A fim de tornar esse trabalho mais efetivo, solicitamos a colaboração de deficientes visuais e também organizações através dos meios digitais. Em conversa com usuários membros de uma associação de deficientes visuais sobre os sites que eles tem maior dificuldade de acesso, foram sugeridos: sites governamentais (federais, estaduais e municipais) que possuem proteção com números, códigos e imagens que não são acessíveis, diversos sites de compras, provedores de filmes e séries, como a Netflix, nos quais os usuários relatam dificuldade ao acessar o conteúdo, também foi relatada dificuldade de acesso em aplicativos de rede sociais e seus lançamentos de atualizações sem a realização de testes de acessibilidade, prejudicando diversos usuários que estavam acostumados a usar a aplicação.

Além dessas, outras dificuldades apontadas são: sites que não abrangem acessibilidade ao conteúdo que está sendo disponibilizado, como o caso de sites que reconhecem o leitor de tela, mas não são ajustados e fazem com que o leitor leia informações às vezes sem sentido; inversão de cores e aumento de fonte que muitas vezes não são adequadas; ausência de responsividade causando sobreposições de conteúdo; imagens ou vídeos somente com música sem descrição do que está se passando; Capchas de verificação por meio de áudio de péssima qualidade ou em outro idioma, como inglês; itens em sites de compra que não possuem uma descrição adequada das características físicas da mercadoria, somente o peso e a altura não permitem que o deficiente saiba ao certo como é o produto, tendo sempre que pedir ajuda para alguém e deixando de agir de forma autônoma.

Em contato com a Mayra Ribeiro, uma deficiente visual de baixa visão, assistente social, youtuber pelo canal Quem Não Viu a Mayra Vê e criadora da hastag \#InstagramAcessivel, sobre suas experiências na internet, ela afirma que muitas vezes as pessoas veem os indivíduos com deficiência com uma lógica capacitista, como se fossem inaptos para cuidar da própria vida. Também afirma ser necessário levantar protestos sobre ausência de acessibilidade, não com o intuito de sensibilizar, mas sim conscientizar os indivíduos acerca das dificuldades que os deficientes visuais encontram em um meio tão importante para suas vidas, capaz de tornar coisas que eram impossíveis em possíveis, mas que ainda há melhorias a serem realizadas, visto que, muitas vezes, recebem um descaso de aplicações, como o Instagram, que lança versões novas sem testar recursos de acessibilidade, prejudicando diversos usuários.

Atualmente, em meio ao cenário da pandemia do novo Coronavírus (SARS-CoV-2 e a Covid-19, doença por ele provocada), seguindo as medidas da OMS em evitar ao máximo sair de suas residências, o mundo todo tem se tornado mais digital do que nunca. Como solução para evitar distanciamento social, a conexão com a internet tem sido a principal forma de se informar, estudar, conversar com outras pessoas, fazer compras, distrair e há até mesmo um aumento de iniciativas das empresas para que os funcionários atuem de suas residências. Contudo, decorre um agravo para os deficientes pela falta de acessibilidade, desde estudantes e trabalhadores que relatam uma grande dificuldade de acesso a plataformas de vídeo conferência como, por exemplo, o Google Meet, como de indivíduos que eram acostumados a sair e resolver seus afazeres de forma autônoma e passaram a depender de outros para os ajudar no meio digital.

Um cenário que mais do que nunca mostra a necessidade de acessibilidade. No período de 28 de maio a 05 de julho de 2020, realizamos a aplicação de questionário online sobre Acessibilidade na Web para desenvolvedores, 
tendo sido obtidas 75 respostas. Destes, 58,7\% desconheciam a taxa de brasileiros que possuem algum tipo de deficiência, $37.3 \%$ conheciam e $4 \%$ não acreditam que seja um público tão grande. Sobre a formação, perguntamos se foram instruídos durante o período de aula a se preocupar com acessibilidade ao desenvolver sites, aplicativos ou conteúdo para a web (Fig. 3) $51 \%$ disseram que sim, $34 \%$ muito pouco e $15 \%$ não foram instruídos. Quando perguntados sobre o enfrentamento de problemas de acessibilidade ao tentar utilizar a internet de forma autônoma no cenário atual de pandemia: 96\% marcaram que acreditam que as pessoas que possuem algum tipo de limitação estejam tendo problemas com acessibilidade, $2.7 \%$ marcaram que essas pessoas não precisam utilizar a internet e $1.3 \%$ não acreditam que os indivíduos estejam com dificuldades. Acerca da realização de testes de acessibilidade antes de uma publicação (Fig. 4) $91.9 \%$ acham importante, $6.8 \%$ não se acharam capazes de opinar e $1.4 \%$ não acham importante. A respeito dos mecanismos de busca do Google priorizar os sites mais acessíveis, $37.3 \%$ não concordam, $33.3 \%$ concordam e $29.3 \%$ não foram capazes de opinar. Perguntamos se gastariam um tempo a mais para implementar acessibilidade nos seus projetos (Fig.5) 78.7\% responderam sim, $13.3 \%$ não e $8 \%$ não foram capazes de opinar. Em relação aos incentivos por meio das empresas, $53.3 \%$ marcaram não trabalhar para um estabelecimento, $21.3 \%$ apontaram possuir pouco incentivo, $17.3 \%$ não possuem incentivo nenhum e $8 \%$ possuem bastante incentivo. Quanto a conhecer e utilizar a WCAG (Fig. 6) 50,7\% não sabem do que se trata, $42.7 \%$ conhecem, mas não utilizam e $6.7 \%$ seguem as diretrizes. Além dessas questões, deixamos um espaço aberto para acrescentar algo sobre a experiência com acessibilidade na área de desenvolvimento e obtivemos algumas respostas apresentadas na Tabela 1.

\section{TABELA 1}

Respostas de questão aberta

\begin{tabular}{|c|c|}
\hline \multicolumn{2}{|c|}{$\begin{array}{l}\text { Há algo que gostaria de acrescentar sobre } \\
\text { experiências com acessibilidade na área de } \\
\text { desenvolvimento? }\end{array}$} \\
\hline $\mathrm{N}^{\circ}$ Pessoa & Relato \\
\hline 1 & $\begin{array}{c}\text { Me surpreendi pelo } \\
\text { pouco conhecimento que } \\
\text { tenho, obrigada por ter me } \\
\text { enviado o questionário, } \\
\text { vou procurar me informar } \\
\text { mais. }\end{array}$ \\
\hline 2 & $\begin{array}{l}\text { Geralmente as empresas } \\
\text { chegam com um projeto } \\
\text { com pouco tempo, pouco } \\
\text { recurso (pessoas) e pouco } \\
\text { dinheiro. Desta forma, a } \\
\text { prioridade torna fazer a } \\
\text { aplicação, onde } \\
\text { geralmente erram em: } \\
\text { Pouca análise de sistema, } \\
\text { UX/UI, Testes, entre } \\
\text { outros. }\end{array}$ \\
\hline 3 & $\begin{array}{l}\text { O cliente escolhe as } \\
\text { tecnologias a serem } \\
\text { utilizadas, a maioria dos } \\
\text { clientes não tem dinheiro } \\
\text { nem tempo para ficar }\end{array}$ \\
\hline
\end{tabular}

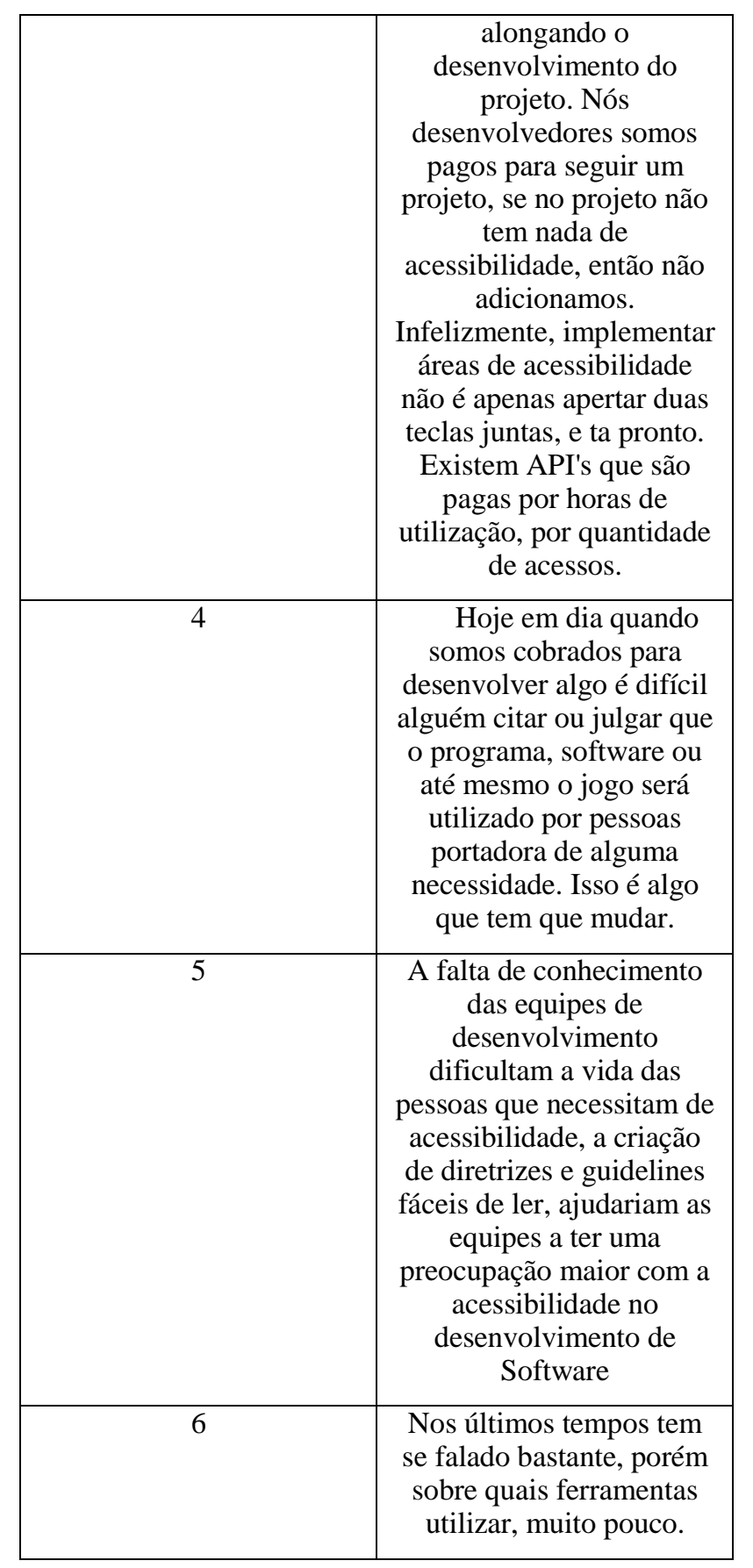

Caso possua formação, você foi instruido durante o pedíodo de aula a se preocupar com acessibilidade ao desenvolver sites, aplicativos ou conteúdos para a internet?

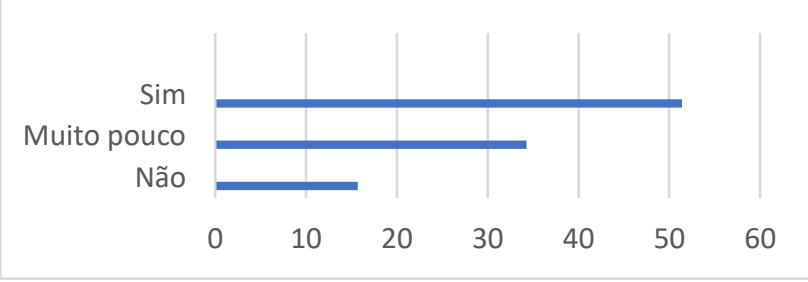

Fig. 3. Gráfico de respostas sobre instrução durante formação. 


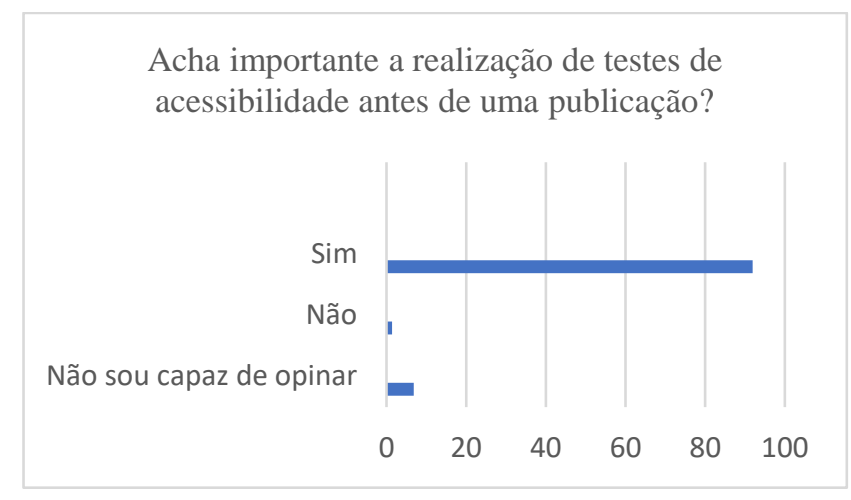

Fig. 4. Gráfico de respostas sobre realização de testes de acessibilidade antes de uma publicação.

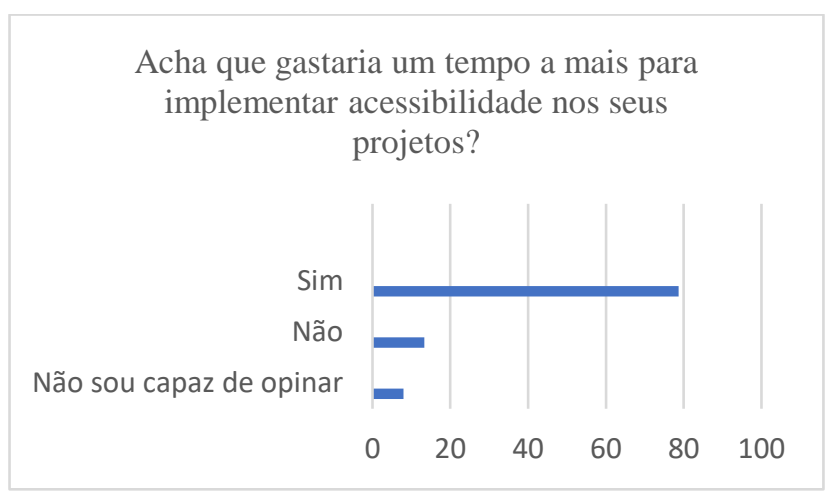

Fig. 5. Gráfico de respostas sobre gastar tempo a mais para implementar acessibilidade nos seus projetos.

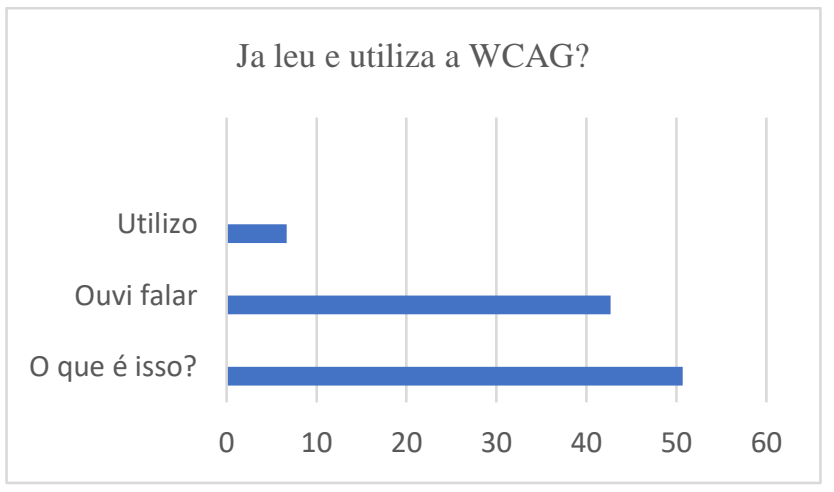

Fig. 6. Gráfico de respostas sobre a WCAG.

Por meio desse questionário podemos concluir que grande parte dos desenvolvedores julgam importante pensar em acessibilidade, mas consideram gastar muito tempo para inclui-la em seus projetos e acabam não fazendo por sempre estarem com pouco tempo para a realização, além da falta de incentivo de empresas e conhecimento das equipes de desenvolvimento, ninguém citar ou julgar que o programa, software ou até mesmo o jogo será utilizado por pessoas portadoras de alguma necessidade, o que dificulta a vida dos que necessitam de acessibilidade.

$\mathrm{O}$ e-book foi produzido para servir de material inicial à desenvolvedores que não possuem conhecimento sobre o tema e querem adquirir o essencial de forma rápida. O material está disponível gratuitamente no site ISSU o título: Introdução à Acessibilidade na Web para Desenvolvedores, pequenas mudanças que fazem a diferença na navegação de pessoas com deficiência visual como mostrado na Fig. 8. O material contém conceitos, exemplos práticos, ferramentas e dicas para começar a compreender e aplicar acessibilidade em conteúdos desenvolvidos para internet, os principais problemas relatados por deficientes visuais e explicações acerca das diretrizes existentes, além de direcionamentos para se aprofundar. $\mathrm{O}$ ebook foi compartilhado com todos que responderam $o$ questionário sobre Acessibilidade na Web e recebeu agradecimentos dos mesmos, como por exemplo, Pessoa1: "Acabei de ler seu livro agora e, achei muuuito legal a sua iniciativa. O conteúdo dele é excelente e muito bom... vai ser de grande valia para mim. "; Pessoa 2: "Parabéns pelo trabalho e mais ainda pelo cuidado com a devolutiva, isso mostra o quanto é importante a participação de todos no desenvolvimento de novas soluções. "; Pessoa 3: "Grato Raíssa! Muito legal e interessante.”.

O e-book está disponível em https://issuu.com/codeclube/docs/ebook-introducao-a-

acessibilidade-na-web-para-dese, acessível gratuitamente. O site ISSU disponibiliza as estatísticas de leitura do e-book, como apontado na Fig. 7, o material teve 90 leituras em um mês.

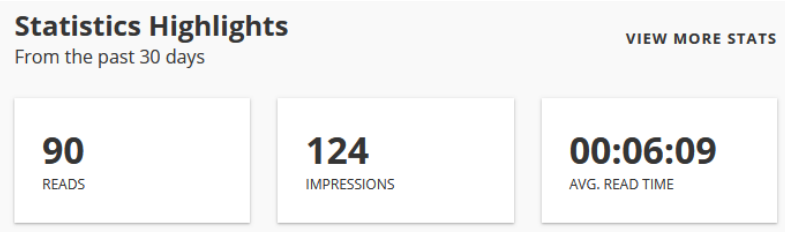

Fig. 7. Acesso ao e-book nos últimos 30 dias (15/10/2020 a 15/11/2020).

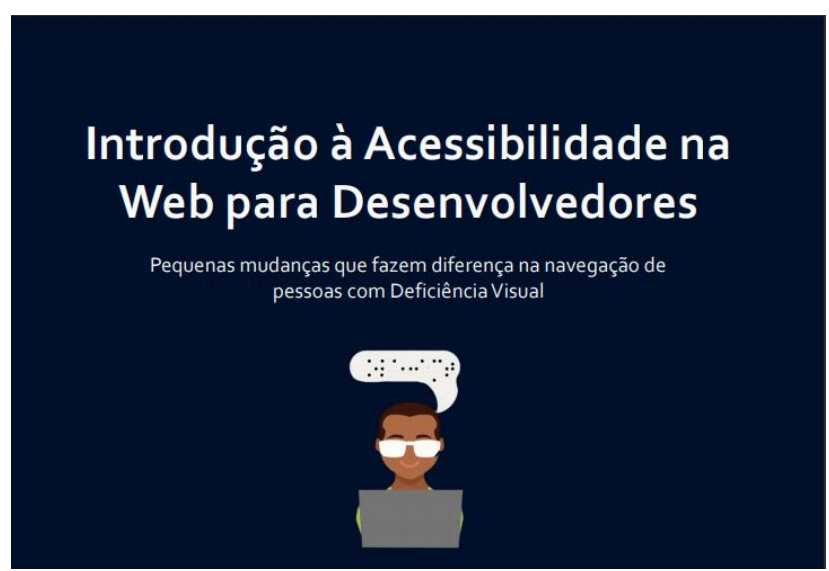

Fig. 8. Capa do e-book: Introdução à Acessibilidade na Web para Desenvolvedores, pequenas mudanças que fazem a diferença na navegação de pessoas com deficiência visual.

O material produzido conta com 60 páginas e 26 tópicos (Fig. 9) que além de mostrar a importância de pensar em acessibilidade também traz os principais conceitos necessários para quem quer começar a colocá-la em prática em seus projetos e não sabe por onde começar. Foram acrescentadas informações do eMAG e da WAI, com o foco principal nesse último por ser o principal arquivo internacional de recomendações de acessibilidade, sendo assim, é explicado quais documentos formam a WAI (Fig. 10), como é a estrutura da WCAG (Fig 11, Fig 12) e o significa cada um dos quatro princípios. $\mathrm{O}$ e-book também 
conta as explicações das diretrizes para os principais problemas relatados por usuários com deficiência visual e alguns exemplos (Fig. 13, Fig. 14, Fig. 15) além de dicas de extensões para o Chrome (Fig.16), ferramentas, curiosidades e links para continuar o aprendizado.

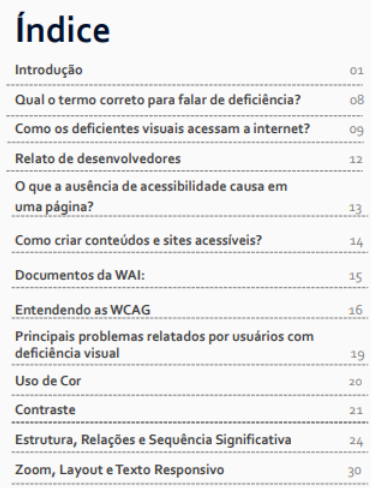

\begin{tabular}{lr}
\hline Conteúdo não-texto & 31 \\
\hline Imagem & 32 \\
\hline Multimidia & 35 \\
\hline Captcha & 38 \\
\hline Elementos Interativos & 39 \\
\hline Conteúdo Invisivel & 40 \\
\hline Idioma da página & 41 \\
\hline Compativel com TA & 42 \\
\hline Resumo & 43 \\
\hline Dicas & 44 \\
\hline Curiosidades & 47 \\
\hline Continue aprendendo & 49 \\
\hline Agradecimentos & 50
\end{tabular}

Fig. 9. Índice do e-book.

\section{Documentos da WAI:}

WCAG - Web Content Accessibility Guidelines: Diretrizes para tornar o conteúdo Web acessivel a todas as pessoas.

ATAG - Authoring Tool Accessibility Guidelines: Diretrizes para ferramentas de autoria, ou seja, dedicadas à criação de conteúdo. Se a ferramenta de autoria conter interfaces de usuário baseadas na Web essas interfaces devem atender aos critérios de sucesso do WCAG.

UAAG - User Agent Accessibility Guidelines: Diretrizes para desenvolvedores de navegadores da Web, media players, tecnologias assistivas e outros tornarem os agentes de usuários (softwares que agem em nome de um usuário) acessiveis às pessoas com deficiência, especialmente para aumentarem a acessibilidade ao conteúdo da Web.

WAI-ARIA - Accessible Rich Internet Applications Suite: Diretrizes para conteúdos dinâmicos e controles avançados de interface de usuários desenvolvidos com Ajax, HTML, JavaScript e tecnologias relacionadas.

Fig. 10. Página 15 sobre os documentos da WAI

\section{Entendendo as WCAG - Estrutura}

Os princípios formam os tópicos principais.

\section{Princípios}

Cada princípio contém recomendações

\section{Recomendações}

As recomendações possuem critérios de sucesso que devem ser seguidos. Cada critério de sucesso é indicado por um nivel de conformidade, que pode ser $A_{l}$ AA ou AAA:

\section{Critérios de Sucesso}

Para atender os critérios de sucesso são disponibilizadas técnicas específicas com exemplos de como o objetivo do critério pode ser atingido.

$$
\text { Técnicas }
$$

Fig. 11. Página 17 sobre a estrutura da WCAG.

\section{Entendendo as WCAG - Níveis de conformidade}

As diretrizes WCAG 2.0 são categorizadas em três niveis de conformidade

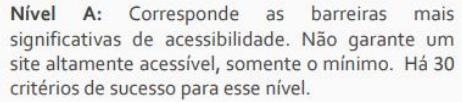

Nivel A: Corresponde as barreiras mais significativas de acessibilidade. Não garante um site altamente acessivel, somente o minimo. Há 30 critérios de sucesso para esse nivel.

Nivel AA: Satisfaz uma gama maior de critérios. Acessivel para a maioria dos usuários, sob a maior parte das circunstâncias. Há 20 critérios de sucesso para esse nivel.

Nivel AAA: Garante um nivel otimizado de acessibilidade. Há 28 critérios de sucesso para esse nivel.

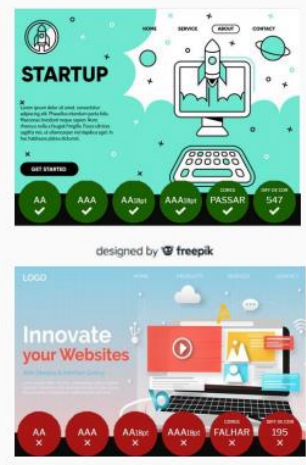

Fig. 12. Página 18 sobre os níveis de conformidade da WCAG.

\section{Uso de Cor - Nível A}

A cor não pode ser usada como o único meio visual de transmitir informações, indicar uma ação, solicitar resposta ou distinguir um elemento visual.
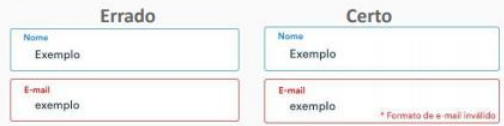

Para qualquer conteúdo onde as diferenças de cor são usadas para transmitir informações, verifique se as mesmas informações estão disponiveis através de sugestões de texto.

A maioria dos usuários podem visualizar rapidamente o conteúdo para localizar informaçōes transmitidas usando diferenças de cor. Os usuários que não conseguem ver a cor poder procurar ou ouvir sugestões de texto e pessoas que usam displays braile ou outras interfaces táteis podem detectar sinais de texto por toque.

Fig. 13. Página 20 sobre o uso da cor.

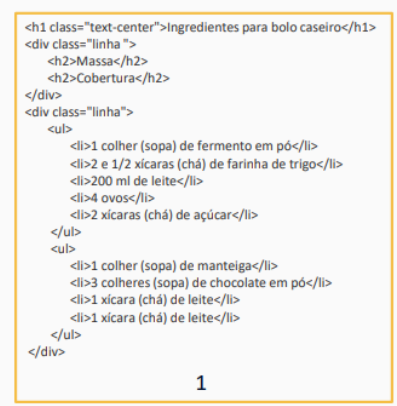

$$
\begin{gathered}
\text { "Ingredientes para bolo caseiro } \\
\text { Massa } \\
\text { Cobertura } \\
1 \text { colher soma de fermento em pó } \\
2 \mathrm{e}^{1 / 2} \text { xicaras de farinha de trigo } \\
200 \mathrm{ml} \text { de leite } \\
4 \text { ovos } \\
2 \text { xícaras (chá) de açúcar } \\
1 \text { colher (sopa) de manteiga } \\
3 \text { colheres (sopa) de chocolate em pó } \\
1 \text { xicara (chá) de leite } \\
1 \text { xicara (chá) de leite" }
\end{gathered}
$$

Seria possivel identificar quais os ingredientes da massa e os da cobertura do bolo caseiro apenas lendo esse texto?

\section{Introduçäo ̇̇ Acessibilidade na Web para Desenvolvedores}

Fig. 14. Página 27 apresentando problema de estrutura e sequência significativa que o leitor de tela pode encontrar. 


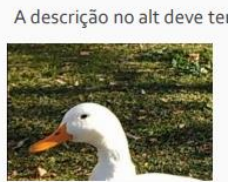

ng src="images/pato.jpg"

alt="Perfil de pato branco com bico alaranjado na

<es

Descrições longas devem ser inseridas no texto fora da imagem, dentro do figcaption com um id, este texto é associado à imagem através do atributo longdesc ou aria-describedby
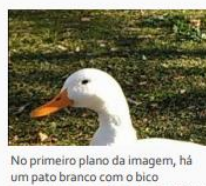
ranjado de perfil. Ao fundo, ha gramado verde com follas secas

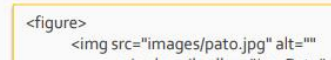

aria-describedby ="imgPato"

figcaptions

$<$ id="imgPato">Noprimeiro plano da imagem, há pato branco com obico alana gramado verde com follhas secas espalhadas. $<$ <figcaption> $<<$ figure $>$

Fig. 15. Página 33 mostrando exemplos corretos de descrições alternativas para uma imagem.

\section{Dicas}

Extensões para o Chrome
$\begin{aligned} & \text { Colour Contrast Checker } \\ & \text { Verifica o contraste entre as diferentes combinações de cores em relação } \\ & \text { aos padrões WCAG. }\end{aligned}$
$\begin{aligned} & \text { Accessibility Insights for Web } \\ & \text { Ajuda os desenvolvedores a encontrar e corrigir rapidamente os } \\ & \text { problemas de acessibilidade. }\end{aligned}$
WAVE Evaluation Tool
injetando icones e indicadores em sua página.
NoCoffee
Simulador de visão útil para compreender os problemas enfrentados por
pessoas com problemas de visão leves a extremos.

Fig. 16. Página 46 sobre dicas de extensões para o Chrome.

\section{CONCLUSÃO}

A partir do levantamento e análise sobre a importância de atender aos requisitos de acessibilidade para pessoas com deficiência visual ao desenvolver conteúdo ou páginas web, levando em consideração o cenário atual, é possível concluir a extrema importância da conscientização sobre o desenvolvimento acessível. Existe um grande número de deficientes que enfrentam dificuldades no meio digital devido à falta de acessibilidade de sites e softwares, visto que somente os recursos da tecnologia assistiva não são capazes de garantir o acesso ao conteúdo de uma página web. Para tal, é necessário que os desenvolvedores tenham consciência de que existem usuários que não podem utilizar teclado e/ou mouse e necessitam de tecnologias assistivas específicas para navegar, que só funcionaram corretamente se o desenvolvimento da página estiver de acordo com recomendações de acessibilidade.

Portanto, a elaboração do e-book gratuito como forma de auxiliar os desenvolvedores a saberem o essencial sobre acessibilidade e onde buscar se aprofundar quando forem trabalhar em projetos é de grande valia para a sociedade como um todo e tem recebido comentários positivos dos leitores, que comprovam sua utilidade.

A pesquisa realizada é de suma importância para a o corpo social, pois além de proporcionar conscientização difunde as leis e diretrizes que tratam de acessibilidade na internet.

\section{AGRADECIMENTOS}

A todos que participaram e contribuíram, direta ou indiretamente para desenvolvimento deste projeto, em especial a Mayra Ribeiro, Kattia Penaforte, Leondeniz de Freitas e associação dos deficientes visuais ADVPATOS por todo o incentivo, divulgação e disponibilidade em contribuir com o levantamento de dados que foram fundamentais para o desenvolvimento da pesquisa.

\section{REFERÊNCIAS}

BRASIL. Constituição (1988). Constituição da República Federativa do Brasil de 1988. Brasília, DF: Presidência da República. Disponível em: http://www.planalto.gov.br/ccivil_03/Constituicao/ Constituicao.htm. Acesso em: 10 mar. 2020.

BRASIL. DECRETO No 5.296. 2004. Brasília, DF: Presidência da República. Disponível em: http://www.planalto.gov.br/ccivil 03/decreto/d3298. htm Acesso em: 10 mar. 2020.

BRASIL. DECRETO No 9.522. 2018. Disponível em: http://www.planalto.gov.br/ccivil_03/Ato20152018/2018/Decreto/D9522.htm. Acesso em: 10 mar. 2020.

BRASIL. Lei Brasileira de Inclusão da Pessoa com Deficiência. 2015. Brasília, DF: Presidência da República. Disponível em: http://www.planalto.gov.br/ccivil 03/ Ato20152018/2015/Lei/L13146.htm. Acesso em: 10 mar. 2020.

FREITAS, L. C. POR UMA WEB MAIS INCLUSIVA: noções básicas de acessibilidade online, 2019. 33 p. Disponível em: https://www.amazon.com.br/Poruma-MaisInclusiva-acessibilidade-

ebook/dp/B07Z9MXDH4. Acesso em: 25 maio 2020.

GASPARETTO, Profa. Dra. Maria Elisabete Rodrigues Freire. Perda visual em idosos. UNICAMP. Disponivel em: https://www.fcm.unicamp.br/fcm/auxiliosopticos/perda-visual-em-idosos. Acesso em: 18 maio 2020.

GIL, Marta (org.). Deficiência Visual. Mec. Secretaria de Educação A Distância, Brasília, n. 1, p. 1-80, 2000. Disponível em: http://portal.mec.gov.br/seed/arquivos/pdf/deficienci avisual.pdf. Acesso em: 15 maio 2020.

IBGE. Censo 2010: população brasileira envelhece em ritmo acelerado. população brasileira envelhece em ritmo acelerado. 2010. Disponivel em: https://censo2010.ibge.gov.br/noticias- 
censo $?$ view $=$ noticia $\& i d=1$ \&idnoticia $=1272 \&$ busca $=1 \& t=i b g e$-populacao-brasileira-envelhece-ritmoacelerado. Acesso em: 19 maio 2020.

IBGE. População: pessoas com deficiência. PESSOAS COM DEFICIÊNCIA. 2018. Disponivel em: $\quad$ https://educa.ibge.gov.br/jovens/conheca-obrasil/populacao/20551-pessoas-comdeficiencia.html.. Acesso em: 18 maio 2020.

KANASHIRO, Milena. A cidade e os sentidos: sentir a cidade. Desenvolvimento e Meio Ambiente. UFPR, n. 7, p. 155-160, jun. 2003. Disponível em: https://revistas.ufpr.br/made/article/view/3051/2442 Acesso em: 05 maio 2020.

MWPT. $3^{\circ}$ Estudo de acessibilidade do Movimento Web para Todos nos sites brasileiros. 2019. Disponível em: https://mwpt.com.br/3o-estudo-deacessibilidade-do-movimento-web-paratodos-nossites-brasileiros/. Acesso em: 21 maio 2020.

NASCIMENTO, Tânia Peres do. Inclusão Digital e Acessibilidade para Deficientes Visuais. Ietec, Belo Horizonte, v. 0, n. 0, p. 1-4, 09 abr. 2015. Disponível em:

https://www.ietec.com.br/clipping/2015/boletim/201 6/janeiro/ti-jan-inclusao-digital-acessibilidadedeficientes-visuais.pdf. Acesso em: 19 maio 2020.

NAVARRO, Juliana Jobim. A INCLUSÃO SOCIAL DOS DEFICIENTES VISUAIS E A PUBLICIDADE BRASILEIRA: um breve panorama. 2012. $62 \mathrm{f}$. Monografia (Especialização) - Curso de Comunicação Social, Audiovisuais e Publicidade, Universidade de Brasília - Unb, Brasília. Disponivel em:

https://bdm.unb.br/bitstream/10483/4259/1/2012 Jul ianaJobimNavarro.pdf. Acesso em: 19 maio 2020.

OTTAIANO, José Augusto Alves; ÁVILA, Marcos Pereira de; UMBELINO, Cristiano Caixeta; TALEB, Alexandre Chater. As Condições de Saúde Ocular no Brasil 2019. São Paulo: Conselho Brasileiro de Oftalmologia, 2019. 104 p. Disponivel em: http://www.cbo.com.br/novo/publicacoes/condicoes saude ocular brasil2019.pdf.. Acesso em: 18 maio 2020
PASSOS, Jeane do Reis; VIEIRA, Ricardo Quintão. DESENVOLVENDO COMPETENCIAS EM INFORMAÇÃO PARA DEFICIENTES VISUAIS: estudo de caso. : ESTUDO DE CASO. ACB, Florianópolis, v. 13, n. 01, p. 276-281, jun. 2008. Disponivel em: https://revista.acbsc.org.br/racb/article/view/559.Ac esso em: 19 maio 2020.

Pesquisa nacional de saúde. 2013 : ciclos de vida : Brasil e grandes regiões / IBGE, Coordenação de Trabalho e Rendimento. - Rio de Janeiro: IBGE, 2015. $92 \quad$ p. Disponivel em https://biblioteca.ibge.gov.br/visualizacao/livros/liv9 4522.pdf. Acesso em: 10 mar. 2020.

PETERSEN, D. A. W.; KALEMPA, V. C.; PYKOSZ, L. C.. Envelhecimento e Inclusão Digital. Extensio, Florianópolis, v. 10, n. 15, p. 1-9, 2013. Disponível em:

https://periodicos.ufsc.br/index.php/extensio/article/ view/27184. Acesso em: 03 maio 2020.

SCHWEITZER, Fernanda. A sociedade e a informação para os deficientes visuais: relato de pesquisa. : relato de pesquisa. Acb, Florianópolis, v. 12, n. 02, p. 273-285, dez. 2007. Disponível em: https://revista.acbsc.org.br/racb/article/view/485..

Acesso em: 19 maio 2020

SONZA, Andréa Poletto (org.). Acessibilidade e tecnologia assistiva: pensando a inclusão sociodigital de PNEs. Bento Gonçalves - Rs: Setec/mec, 2013. Disponivel em: http://forumeja.org.br/sites/forumeja.org.br/files/ace ssibilidade-tecnologiaassistiva\%20(texto\%20complementar).pdf Acesso em 10 mar. 2020.

W3C. About World Wide Web Consortium. Disponivel em: http://www.w3.org/Consortium. Acesso em: 24 mar. 2020.

WEBAIM. Screen Reader User Survey \#7 Results. $2017 . \quad$ Disponivel em: https://webaim.org/projects/screenreadersurvey7/\#br owsers. Acesso em: 22 mar. 2020. 